\title{
Manipulation of Arthropod Sex Determination by Endosymbionts: Diversity and Molecular Mechanisms
}

\author{
W.-J. Ma ${ }^{\mathrm{a}} \quad$ F. Vavre ${ }^{\mathrm{b}} \quad$ L.W. Beukeboom ${ }^{\mathrm{a}}$ \\ ${ }^{a}$ Evolutionary Genetics, Centre for Ecological and Evolutionary Studies, University of Groningen, \\ Groningen, The Netherlands; ${ }^{b}$ Laboratoire de Biométrie et Biologie Evolutive, Université de Lyon, Villeurbanne, France
}

\section{Key Words}

Arthropods · Endosymbiont · Epigenetics · Hormonal signaling · Molecular mechanism · Sex determination . Sexual differentiation diploidy. Future directions on how the study of endosymbiotic manipulation of host reproduction can be key to further studies of arthropod sex determination are shown.

(c) 2013 S. Karger AG, Basel

Arthropods cover over 1.2 million described species that account for about $80 \%$ of all known living animal species. They have colonized virtually all habitats on Earth. In line with this broad adaptation to many conditions, they exhibit an enormous variety of life histories and reproductive modes. They also show surprisingly large variation and turnover in sex determination systems. It is therefore a prime group of organisms to study how changes in sex determination mechanisms come about, a current topic in evolutionary biology that is not well understood. A particular aspect of arthropod biology is their frequent infection with microorganisms that can be mutualistic, parasitic, or commensal. A specific group are endosymbionts, such as Wolbachia, Cardinium, Rickettsia, Spiroplasma, and Arsenophonus bacteria, microsporidia and viruses, that manipulate their host's reproduction in a variety of ways [reviewed in Hurst et al., 1996; Werren et al., 2008; Kageyama et al., 2012]. These intracellular parasites are maternally transmitted through

\section{KARGER}

E-Mail karger@karger.com

www.karger.com/sxd
(C) 2013 S. Karger AG, Basel

$1661-5425 / 13 / 0083-0059 \$ 38.00 / 0$
Wen-Juan Ma

Evolutionary Genetics, Centre for Ecological and Evolutionary Studies University of Groningen, PO Box 11103

NL-9700 CC Groningen (The Netherlands)

E-Mail wenjuanma84@gmail.com 
the egg cytoplasm. As males are an evolutionary dead end for them, any symbiont having the capability to increase female production is at an advantage and can invade host populations [Partridge and Hurst, 1998; Duron et al., 2008; Werren et al., 2008; Cordaux et al., 2011]. This can be realized through causing thelytokous parthenogenesis, male killing, or feminization. As they enhance their own transmission at the expense of their host's fitness, their presence generates genetic conflicts between the 2 sexes and possibly an ensuing co-evolutionary arms race over offspring sex [Hurst and Werren, 2001; Werren, 2011]. It has been suggested that such a conflict can drive the evolution of changes in host reproduction and sex determination mechanisms [Werren and Beukeboom, 1998; Stouthamer et al., 2010; Cordaux et al., 2011; Beukeboom, 2012]. Hence, these endosymbionts may be important evolutionary drivers of turnover in arthropod sex determination.

Here, we review and discuss the current knowledge about manipulative actions of endosymbionts in arthropods. We first briefly summarize the current knowledge about arthropod sex determination and the 4 major endosymbiotic manipulation types of host reproduction. We then move to a specific focus on how symbionts might interfere with host sex determination based on the current knowledge about the molecular basis of host manipulation. We end by proposing future directions on how these reproductive phenotypes may be key to further studies of arthropod sex determination. As epigenetic effects are becoming more apparent in insect development, we pay special attention to the possibility of epigenetic regulation.

\section{Arthropod Sex Determination}

Sex determination in arthropods is generally genetically determined by factors on sex chromosomes, with some exceptions in crustaceans in which it is under either temperature or photoperiod control [Bouchon et al., 1998; Cordaux et al., 2011; Kageyama et al., 2012]. Most knowledge comes from insects where sex determination occurs through a cascade of genes with a highly conserved master switch gene (doublesex) at the bottom but more divergence in the upstream genes (e.g. transformer) and the primary signals at the top of the cascade [Wilkins, 1995; Beye et al., 2003; Verhulst et al., 2010; Beukeboom, 2012]. The chromosomal constitutions serve as primary signals and vary between orders. Most insect orders (22 out of 29) have male heterogamety with either an XO or
XY chromosomal constitution [Blackman, 1995; Beukeboom and Perrin, 2014]. For instance, most Diptera (flies) and Coleoptera (beetles) have male heterogamety with presence of a Y chromosome (XX/XY), and most Orthoptera (grasshoppers), Odonata (dragonflies), and Mantodea (mantids) have male heterogamety without a Y (XX/ $\mathrm{XO}$ ). All Lepidoptera (butterflies, moths) and Trichoptera (caddisflies) have female heterogamety (either ZW/ $\mathrm{ZZ}$ or ZO/ZZ). Hymenoptera (sawflies, wasps, bees, and ants) and Thysanoptera (thrips) do not have specific sex chromosomes and reproduce by haplodiploidy (haploid males, diploid females). In addition to these common types of sex determination, more rare variations occur, such as multiple sex chromosomes and X chromosome or paternal genome loss [Bull, 1985; Sánchez, 2008].

The chromosomal constitutions are translated into different downstream signals that are also diverse among insect orders. In diploids they include X (or Z) chromosome counting elements, dominant masculinizing factors, and dominant feminizing factors. In haplodiploids, allelic complementarity at one or more sex determination loci and maternal effect genetic imprinting have been documented. In most species these signals converge downstream to regulate a key sex determination gene transformer which directly regulates the sex master switch gene doublesex ( $d s x)$ [Bull, 1985; Nöthiger and Steinmann-Zwicky, 1985; Wilkins, 1995; Marín and Baker, 1998; Raymond et al., 1998; Schütt and Nöthiger, 2000; Graham et al., 2002; Saccone et al., 2002; Sánchez, 2008; Verhulst et al., 2010; Gempe and Beye, 2011]. Exceptions seem to occur in Lepidoptera where transformer has not been found [Suzuki et al., 2001, 2008; Geuverink and Beukeboom, this issue]. Doublesex in turn regulates genes for sex specific development [Wilkins, 1995; Raymond et al., 1998; Schütt and Nöthiger, 2000] and together with the fruitless gene regulates sexual differentiation including sexual behavior [Waterbury et al., 1999; Rideout et al., 2010].

Much less is known about arthropod sex determination outside of the insects, in particular at the level of genes. In crustaceans, heterogametic sex determination appears to be most common [Legrand et al., 1987]. The transformer gene has been only identified in the water flea Daphnia magna but does not show sex differences in expression or splicing patterns, rendering it unlikely to be involved in sex determination [Kato et al., 2010]. An important difference from insects is that sex determination in crustaceans is an endocrine process mediated by the androgenic hormone synthesized by the androgenic gland [Ventura et al., 2011]. Basically, individuals have all 
the genetic information to develop as male or female, but their fate is determined by a feminizing gene that inhibits the development of the androgenic gland and the synthesis of the androgenic hormone. In absence of the androgenic hormone, female differentiation is induced. In Acari (mites, ticks), both diploidy and haplodiploidy occur, but virtually nothing is known about the genetic regulation of sex determination [Norton et al., 1993; Arakaki et al., 2001]. The same holds for myriapods (millipedes, centipedes) that have male heterogametic sex determination [Fontanetti et al., 2002]. No sex determination genes have been identified in any of these arthropod groups yet.

\section{Endosymbiont Diversity and Manipulation Types}

Over $40 \%$ of all arthropods are infected with endosymbionts that live in the cytoplasm of their cells and are vertically transmitted through the eggs of females [Werren, 1997; Werren and O'Neill, 1997; Zchori-Fein et al., 2001; Zchori-Fein and Perlman, 2004; Zug and Hammerstein, 2012]. Some of these are obligate mutualists such as Buchnera in aphids [Douglas, 1998; Koga et al., 2003], but many others are reproductive parasites. The most prevalent of these host manipulators are the alpha-proteobacteria Wolbachia pipientis and Rickettsia sp., the bacteroidetes Cardinium hertigii, the gamma-proteobacterium Arsenophonus, and the mollicutes Spiroplasma poulsonii and S. ixodetis which belong to very distantly related bacterial clades [Duron et al., 2008]. Four broad categories of host reproductive manipulation are distinguished: induction of cytoplasmic incompatibility between egg and sperm, thelytokous parthenogenetic reproduction, killing of male offspring, and feminization of genotypic males [Hurst et al., 2002; Werren et al., 2008; Kraaijeveld et al., 2011]. The molecular genetic details of the mechanisms by which these endosymbionts exert the effects on their hosts are not yet well known. Given the diversity of effects and the variety of microorganisms involved, different questions arise: is this true convergence or are horizontal gene transfers between symbionts involved? If this is convergence among symbionts, is it only at the phenotypic level or also at the mechanistic level? How can we explain the seemingly easy evolution of these manipulations? Do different types of manipulation share common mechanisms? Answering these questions requires a better understanding of the molecular mechanisms at play which in turn will pave the way for better understanding the basic processes of sex determination and their evolution. Before getting into these questions, we briefly pre-

Endosymbiotic Manipulation of

Arthropod Sex Determination sent the different types of reproductive manipulations. The common theme is that host sex determination is somehow manipulated by the endosymbionts to increase their own transmission vertically through females. Recent evidence suggests that some of these manipulative actions may be attained by directly interfering with host sex determination genes [Beukeboom, 2012; Sugimoto and Ishikawa, 2012].

\section{Cytoplasmic Incompatibility}

Cytoplasmic incompatibility (CI) is considered as the most widespread endosymbiotic manipulation among arthropods [Werren et al., 2008; Kageyama et al., 2012]. It has been found in Coleoptera, Diptera, Hymenoptera, Hemiptera, Lepidoptera, Orthoptera, Isopoda, Trombidiformes, and Mesostigmata [Tram and Sullivan, 2002; Werren et al., 2008; Kageyama et al., 2012] (table 1). Despite this broad phylogenetic distribution, CI induction has thus far only been attributed to Wolbachia and Cardinium. CI is a form of post-zygotic reproductive isolation occurring in crosses between infected males and uninfected females or when mates harbor different strains of the symbiont [O'Neill et al., 1992; Turelli and Hoffmann, 1995; Werren, 1997]. In diploid species, incompatible crosses produce severe cell cycle defects in the malederived pronucleus, resulting in an abnormal chromosome condensation at metaphase and aberrant segregation during anaphase of the first mitotic division which leads to early embryonic mortality [Serbus et al., 2008]. In haplodiploids, CI crosses lead to male-biased offspring, because elimination of the paternal chromosome set restores haploidy and results in male development [Breeuwer and Werren, 1990, 1993; Breeuwer, 1997; Raychoudhury and Werren, 2012]. However, in some species haploid embryos may also die in an early stage, depending on the host species, genotype, or the symbiont complement [Vavre et al., 2000, 2001; Perrot-Minnot et al., 2002; Hunter et al., 2003; Mouton et al., 2005] due to the incomplete elimination of paternal chromosomes resulting in aneuploidy and thus unviable embryos [Tram et al., 2006]. The exact mode of action is not fully understood, but the current model is based on a chromosome marking effect during male gametogenesis that is rescued in the egg if endosymbionts (inherited from the mother via the egg cytoplasm) of a similar type are present [Werren et al., 2008]. CI thus results from a delayed paternal effect as Wolbachia or Cardinium are not present in the sperm. The sequencing of a CI-inducing Cardinium genome was expected to provide insights into the mechanisms of CI, but the recent publication of this genome did not yield 
Table 1. Association between endosymbionts, arthropod host orders, and host sex determination (summarized from Kageyama et al. [2012])

\begin{tabular}{|c|c|c|c|}
\hline Manipulation phenotype & Endosymbiont & Arthropod host order & $\begin{array}{l}\text { Host sex determination } \\
\text { (number of species reported) }\end{array}$ \\
\hline Cytoplasmic incompatibility & $\begin{array}{l}\text { Wolbachia } \\
\text { Cardinium }\end{array}$ & $\begin{array}{l}\text { Coleoptera } \\
\text { Diptera } \\
\text { Hymenoptera } \\
\text { Hemiptera } \\
\text { Lepidoptera } \\
\text { Orthoptera } \\
\text { Isopoda } \\
\text { Trombidiformes } \\
\text { Mesostigmata }\end{array}$ & $\begin{array}{l}\text { XY or XO male heterogamety (7) } \\
\text { XY or XO male heterogamety (18) } \\
\text { haplodiploidy (9) } \\
\text { XY male heterogamety (3) } \\
\text { ZW or ZO female heterogamety (5) } \\
\text { XO or XY male heterogamety (6) } \\
\text { ZW female heterogamety (2) } \\
\text { haplodiploidy (6) } \\
\text { unknown (1) }\end{array}$ \\
\hline Parthenogenesis & $\begin{array}{l}\text { Wolbachia } \\
\text { Cardinium } \\
\text { Rickettsia }\end{array}$ & $\begin{array}{l}\text { Hymenoptera } \\
\text { Thysanoptera } \\
\text { Trombidiformes }\end{array}$ & $\begin{array}{l}\text { haplodiploidy (24) } \\
\text { haplodiploidy (1) } \\
\text { haplodiploidy (2) }\end{array}$ \\
\hline Feminization & $\begin{array}{l}\text { Wolbachia } \\
\text { Cardinium } \\
\text { Microsporidia parasites } \\
\text { Gasteromermis } \\
\text { f factor (unknown) }\end{array}$ & $\begin{array}{l}\text { Lepidoptera } \\
\text { Hemiptera } \\
\text { Hymenoptera } \\
\text { Trombidiformes } \\
\text { Isopoda } \\
\\
\text { Ephemeroptera } \\
\text { Amphipoda }\end{array}$ & $\begin{array}{l}\text { ZW or ZO female heterogamety (2) } \\
\text { XO male heterogamety (1) } \\
\text { haplodiploidy (2) } \\
\text { haplodiploidy ( } 3) \\
\text { ZW female heterogamety (2), } \\
\text { XY male heterogamety (1), } \\
\text { unknown (2) } \\
\text { unknown (1) } \\
\text { unknown (4) }\end{array}$ \\
\hline
\end{tabular}

more information. Interestingly though, it suggests that CI has an evolutionary independent origin in Wolbachia and Cardinium, since no recent horizontal gene transfer between these 2 symbionts has been detected [Penz et al., 2012]. CI-Wolbachia can readily spread in populations, because infected females have an advantage over uninfected females in that they are compatible both with uninfected and infected males [Werren, 1997].

\section{Thelytokous Parthenogenesis}

Several types of endosymbionts have been found to induce thelytokous parthenogenesis including Wolbachia, Cardinium, and Rickettsia [Werren, 1997, 2008; Giorgini et al., 2010] (table 1). Parthenogenesis induction (PI) by microbes entails making the host reproduction independent of fertilization. This results in progeny that consist entirely of females if the parthenogenesis induction is
$100 \%$ effective. Parthenogenetic development of eggs requires special adaptations to the mode of oogenesis, i.e. the diploid complement needs to be restored after meiosis. There are many ways in which this could be accomplished [Suomalainen et al., 1987; Stenberg and Saura, 2009], including several modifications of meiosis, but the mechanisms used by endosymbionts appear rather limited (see below). Moreover, the taxonomic distribution of endosymbiont-induced thelytokous parthenogenesis in arthropods is quite restricted. Thus far, it has only been documented in haplodiploids, like hymenopterans, thrips, and mites (table 1). In these groups, the endosymbionts cause doubling of the chromosomes in the egg without subsequent cell division. Because of haplodiploid sex determination, the haploid eggs that would normally develop into males are converted into diploid eggs that develop into females [Werren et al., 2008]. In other words 
the sex reversal is opposite to that of CI: genetic males are converted into genetic females by changing the chromosome complement of the zygote from haploidy to diploidy. Curing of hosts from their endosymbionts with antibiotics typically results in the production of haploid eggs that develop into males.

Cytological studies on a number of hymenopterans have revealed several different post-meiotic mechanisms of diploidy restoration. In Trichogramma pretiosum, $T$. deion, and T. nr. deion, diploidization is due to a segregation failure of the 2 sets of chromosomes in the first mitotic anaphase [Stouthamer and Kazmer, 1994]. A similar mechanism occurs in Leptopilina clavipes [Pannebakker et al., 2004]. In Muscidifurax uniraptor, however, the normal first mitotic anaphase is followed by fusion of the adjacent first mitotic nuclei [Gottlieb et al., 2002], a process known as gamete duplication. The result is 2 identical sets of chromosomes and completely homozygous progeny. In the mite Bryobia praetiosa, reproduction is functionally apomictic with all progeny identical in genotype to their mother and heterozygosity being maintained [Weeks and Breeuwer, 2001]. The similar functionally apomictic cloning mechanism was also found in the heterozygous offspring of the Rickettsia-infected parasitoid wasp Neochrysocharis formosa [Adachi-Hagimori et al., 2008].

$\mathrm{PI}$ is the ultimate strategy for a maternally transmitted symbiont: as fertilization is superfluous, fixation of the symbiont within populations or entire species is possible. Curing of hosts from their endosymbionts with antibiotics typically results in male production [e.g. Zchori-Fein et al., 2001; Kremer et al., 2009]. However, restoration of sexual lines has yet proved impossible in species in which the endosymbiont is fixed. Sexual traits have decayed either both in males and females, or males partially retain functionality. Two alternative explanations have been proposed. The neutral mutation hypothesis states that if traits involved in sexual reproduction are neutral under asexuality, relaxed selection might take place and allow mutations to accumulate, for instance, in male sexual traits such as courtship behavior and fertility. The selection hypothesis considers that sexual traits decay can be selected in females. First, if sexual traits are costly and no longer provide fitness benefits, they are expected to be strongly negatively selected. This applies more to female than to male sexual traits, like pheromone production, spermatheca functionality, and egg fertilization, because the males are absent under asexuality [Fong et al., 1995; Schwander et al., 2013]. Second, when Wolbachia infection remains polymorphic through inefficient transmis-

Endosymbiotic Manipulation of Arthropod Sex Determination sion of the symbiont, a nucleo-cytoplasmic conflict over sex ratio may select nuclear alleles for higher male production, referred to as 'virginity mutants', which can be achieved by losing the ability to use sperm or losing the ability to mate [Stouthamer et al., 2010]. Whatever the mechanism at play, PI symbionts are associated with loss of traits involved in the normal process of sexual reproduction, and this process can be either neutral or actively selected for which opens up the possibility that endosymbionts take over the role of genes involved in sex determination and sexual differentiation.

\section{Male Killing}

Male killing (MK) is induced by a large diversity of endosymbiont taxa and found in a variety of arthropod host orders (table 1). Wolbachia, Spiroplasma, Rickettsia, Arsenophonus, Flavobacteria, as well as microsporidia have all been reported to cause male killing [reviewed in Hurst and Jiggins, 2000; Kageyama et al., 2012]. Male killing occurs if sons of infected mothers are killed by the endosymbiont during development [Bonte et al., 2008; Werren et al., 2008]. Endosymbiont-induced male lethality has been reported from 6 different arthropod orders, i.e. Coleoptera, Diptera, Pseudoscorpiones, Hemiptera, Lepidoptera, and Hymenoptera [Werren et al., 2008; Kageyama et al., 2012] (table 1). The MK phenotype is variable and can be divided into 2 broad categories according to the timing of action: early male killing at embryonic stages and late male killing at late larval or early pupal stages [Hurst, 1991; Kageyama et al., 2007]. Of interest, male killing is found in species with either male or female heterogamety as well as haplodiploidy which suggests, together with developmental timing variation, that male killing is the outcome of different molecular mechanisms (table 1; fig. 1). Early male killing is typically encountered in species where intra-brood competition is high; killing brothers allows sisters to have more resources for survival. Late male killing is associated with parasites having both vertical and horizontal transmission. The microorganisms gain the maximal benefit from it, because male hosts, which do not contribute to vertical transmission, are killed at the late larval stage when the number of infected cells is maximal allowing for the maximal horizontal transmission [Hurst, 1991; Kageyama et al., 2007; Nakanishi et al., 2008]. Importantly, the presence of male-killing selfish elements leads to selection for host resistance. This is notably what occurred in the butterfly Hypolimnas bolina where Asian populations harbor a dominant resistant allele to the male-killing phenotype, although the mechanistic details are not known yet [Hornett et al., 


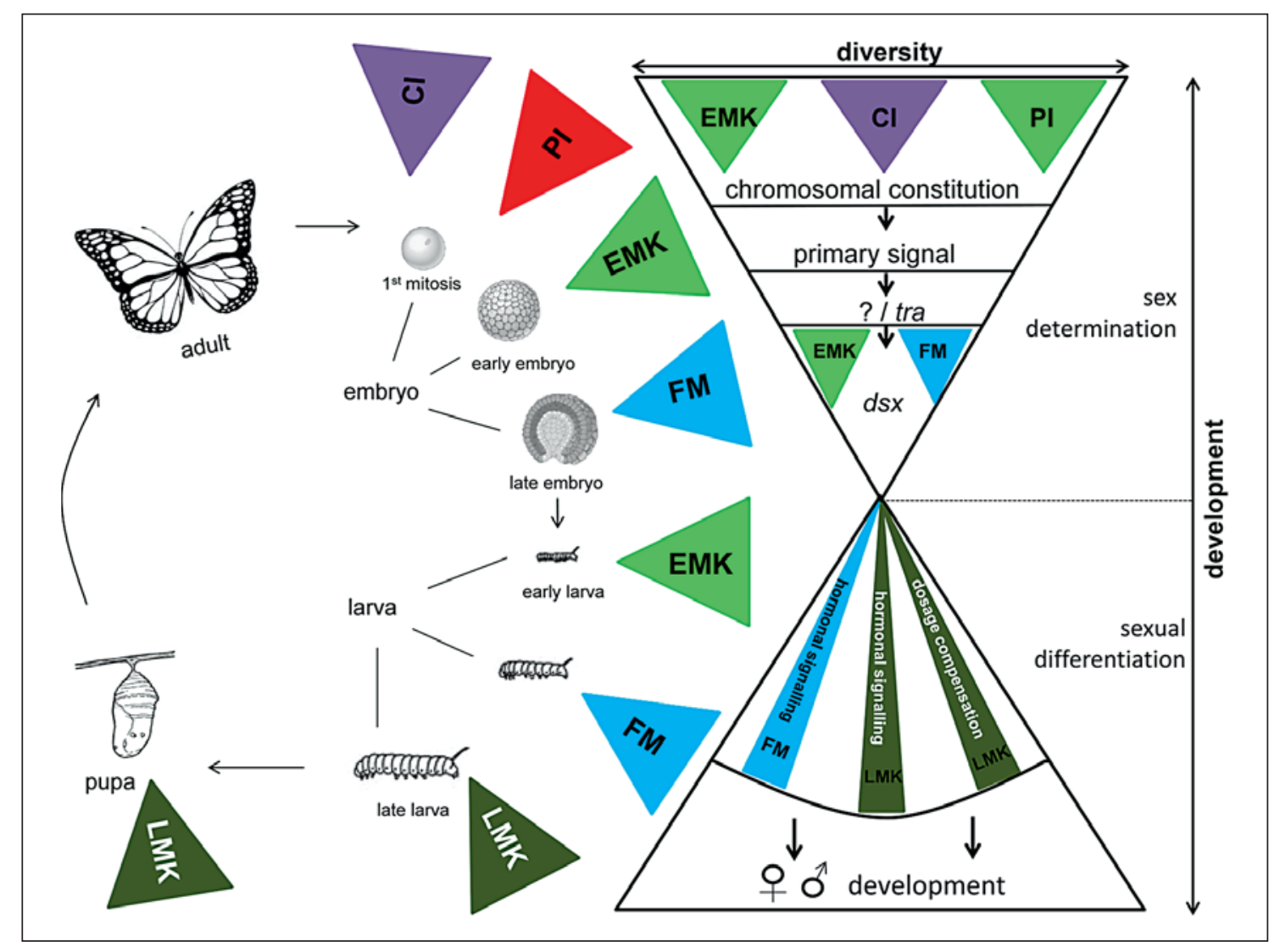

Fig. 1. The 4 manipulation phenotypes of endosymbionts that affect different developmental stages of arthropods (using a butterfly life cycle as an example). Red arrow: thelytokous parthenogenesis induction (PI); purple arrows: cytoplasmic incompatibility (CI), blue arrows: feminization (FM); light green arrows: early male killing (EMK), and dark green arrows: late male killing (LMK) in terms of the developmental stage at which MK occurs. Each arrow indicates the corresponding host developmental stage at which en-

2008]. Interestingly, the rapid spread of resistance has been monitored in natural populations of the South $\mathrm{Pa}$ cific, highlighting both the dynamic nature of these interactions and the intensity of the selective pressures generated by reproductive manipulators [Charlat et al., 2007].

\section{Feminization}

Conversion of genotypic males into phenotypic and functional females is known as feminization (FM) [Bouchon et al., 1998; Kageyama et al., 1998]. Endosymbiont-induced feminization has been reported from 7 arthropod orders: Lepidoptera, Hemiptera, Hymenoptera, Thrombidiformes, Isopoda, Ephemeroptera, and Amphipoda [reviewed in Werren et al., 2008; Kageyama et al., 2012]. Feminization is associated with different sex deter- dosymbiotic manipulation takes place. The sex determination-differentiation pathway is enlarged to depict the position in the gene cascade and timing during development at which endosymbionts interfere. Transformer (tra) is the central gear to transmit the primary signals to the conserved master switch gene doublesex ( $d s x)$ which regulates the downstream sexual differentiation. The question mark next to tra refers to insects in which this gene appears to be absent, such as Lepidoptera. mination mechanisms in these groups, such as male or female heterogamety, haplodiploidy, and some unknown mechanisms for crustacean species (table 1). Feminization seems to be more frequent in crustaceans than in insects which could be due to the easiness to manipulate sexual phenotypes in the former. Indeed, simple manipulation of hormonal levels in crustaceans leads to sex reversion. In the well-studied woodlouse Armadillidium vulgare (Isopoda), Wolbachia feminizes ZZ males by interfering with the production/perception of the androgenic hormone from the male developmental gland during sexual differentiation [Bouchon et al., 2008; Cordaux et al., 2011]. This resembles the shrimp Gammarus duebeni in which microsporidian parasites such as Octosporea effeminans and Nosema granulosis change males into function- 
al females [Bulnheim and Vávra, 1968; Terry et al., 1998; Rodgers-Gray et al., 2004]. Feminization has also been found in insects where different mechanisms could be at play such as disrupting methylation patterns and genetic imprinting in the male-heterogametic leafhopper Zyginidia pullula [Negri et al., 2006, 2009] or altering splicing of doublesex in the female-heterogametic butterfly Eurema mandarina [Narita et al., 2007]. Feminization also occurs in haplodiploid species. Giorgini et al. [2009] found that in Encarsia hispida curing from Cardinium does not lead to haploid but diploid males, suggesting that the endosymbionts are not responsible for genome duplication (parthenogenesis) but rather cause feminization of diploid males. Moreover, in the Cardinium infected mite Brevipalpis phoenicis [Groot and Breeuwer, 2006], consisting exclusively of haploid females, Weeks et al. [2001] reported that curing of the bacterium changes haploid daughters into haploid sons.

Under endosymbiont-induced feminization, scarcity of males within host populations generates a strong nucleo-cytoplasmic conflict. Resistance forms have been detected in some cases, notably in A. vulgare. In this species, together with masculinizing genes, other feminizing factors have been demonstrated but are encoded by the nuclear genome [Juchault and Mocquard, 1993]. There is some evidence that this nuclear feminizing factor originates from a horizontal gene transfer from Wolbachia [Rigaud and Juchault, 1995]. The A. vulgare system is a good illustration of the dynamic nature of sex determination where female and male heterogamety are evolving in response to feminizing Wolbachia [Cordaux et al., 2011]. The high diversity and dynamics of sex determination systems and the absence of sex chromosome differentiation in crustaceans makes it likely that this pattern occurs more widespread in crustaceans [Rigaud, 1997].

\section{Mechanisms of Reproductive and Sex Determination Manipulations}

With respect to genetic mechanisms, we delineate a typology of reproductive manipulations. CI, PI, MK, and FM differ in their actions in relation to the timing at which they interfere with the host sex determination and differentiation processes. Taking the master sex switch gene doublesex as the central point ('bottleneck in an hourglass'), manipulations can target earlier events constituting the primary signals, doublesex itself, or downstream processes including sexual differentiation (fig. 1). This typology integrates phylogenetic and empirical in-

Endosymbiotic Manipulation of Arthropod Sex Determination formation and allows us to consider different reproductive manipulation mechanisms in a phylogenetic context. It indicates that endosymbionts have the potential to undergo rapid evolutionary shifts in phenotypes [Werren, 1997; Jaenike, 2007; Kraaijeveld et al., 2011]. Below, we discuss how mechanisms of reproductive manipulation may be informative for the molecular basis of host sex determination.

\section{Interference with Primary Signals}

Interference with primary sex determination signals concerns notably manipulation of chromosomal behavior. This is clearly established for CI where paternal effects lead to ploidy changes in the early fertilized egg. CI endosymbionts in diploid arthropod species obviously do not interfere with host sex determination, because they cause lethality through haploidization of eggs [Serbus et al., 2008]. However, in haplodiploids, conversion of diploid female eggs into haploid male eggs occurs by changing the zygotic chromosomal constitution that acts as a primary signal for sex determination. This is very similar to PI endosymbionts that also act early during sex determination as they alter the number of chromosomal complements at the end of the first or beginning of the second mitotic division. As transcription is probably limited at that time, PI is certainly a parental effect, but contrary to $\mathrm{CI}$, it is limited to a maternal effect. It is still unknown how endosymbionts precisely alter the molecular regulation of mitosis to induce diploidization of the host eggs. Why parthenogenesis inducing microbes have not been found in diploid species remains another mystery. One explanation is that PI evolves more easily in haplodiploids because of the pre-existing cellular machinery for full development from unfertilized haploid eggs. The interactions between mechanisms of sex determination and PI endosymbionts are particularly complex and further elaborated in the section "Interaction between PI Endosymbionts and Host Haplodiploid Sex Determination". The early MK type can also act on the zygotic chromosome constitution that serves as the primary signal in the host sex determination pathway. In the wasp Nasonia vitripennis, Arsenophonus nasoniae kills male offspring by blocking maternal centrosome formation during oogenesis [Ferree et al., 2008]. In Drosophila bifasciata, infected male embryos show severe defects of chromatin remodeling and spindle organization, a phenotype strikingly similar to the phenotype observed in CI [Riparbelli et al., 2012].

Early acting endosymbionts that alter the chromosomal constitution, a feature of PI, CI, and early MK, suggest similar target host genes that have a relatively broad 


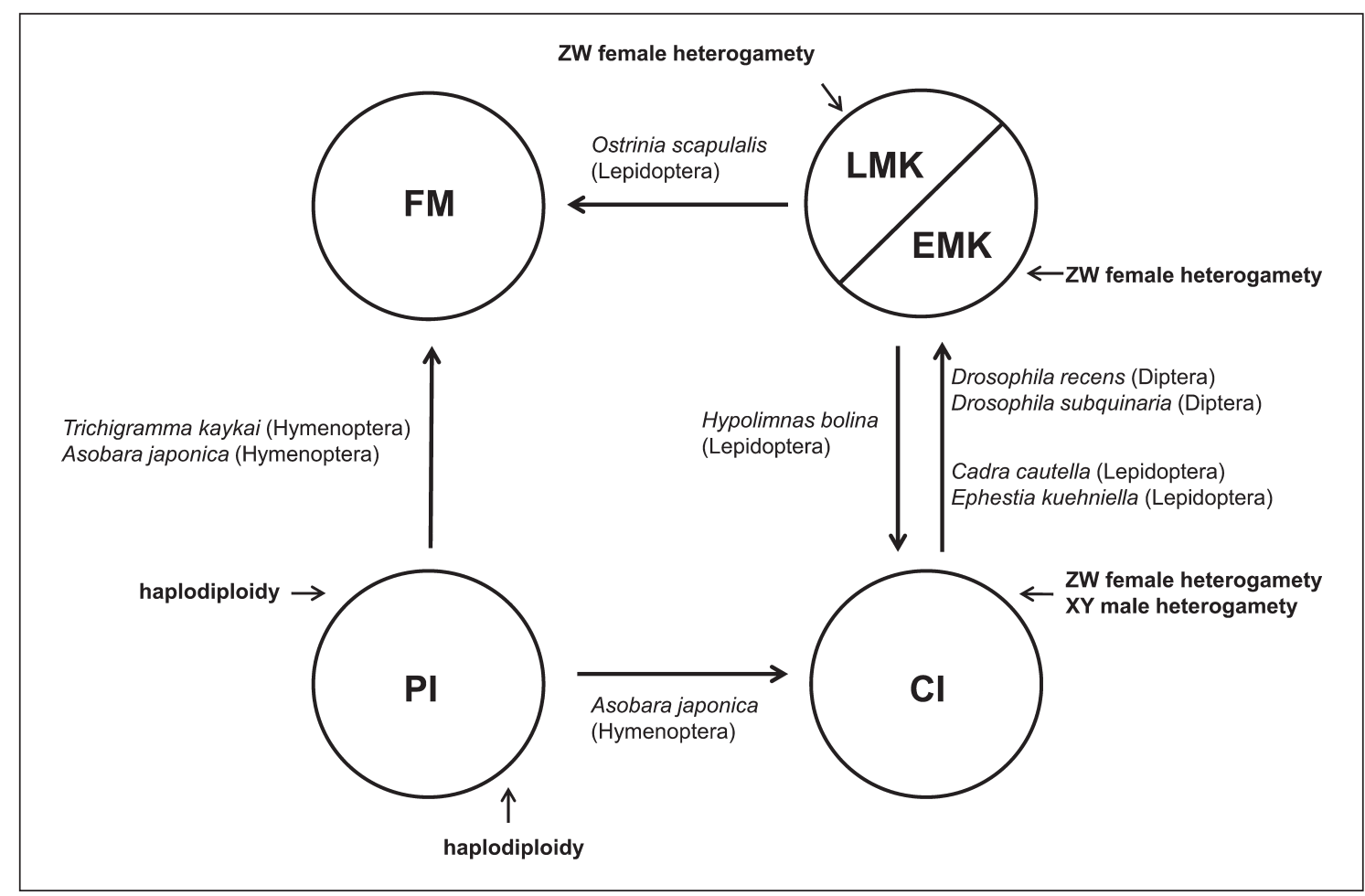

Fig. 2. Transitions between the 4 different manipulative phenotypes of Wolbachia. FM = Feminization; EMK = early male killing; LMK = late male killing; $\mathrm{CI}=$ cytoplasmic incompatibility; PI = thelytokous parthenogenesis induction. The reported species (and orders) are indicated at each arrow as well as their mode of sex determination.

function. This would explain why the manipulations occur in such a diversity of host taxa regardless of their sex determination system. There are many molecules that endosymbionts could target to change the chromosome constitution of the egg. Of particular interest, $\mathrm{CI}$ is associated with impaired histone deposition in the male pronucleus which could lead to activation of cell cycle checkpoints [Landmann et al., 2009]. Other examples include the inhibition of the proper digestion of cohesions that would result in failure of chromosome separation during meiosis or mitosis [Ferree et al., 2008; Schurko et al., 2009]. A similar effect might be achieved by interfering with signals that regulate the $\mathrm{M}$ checkpoint in the cell cycle. An interesting class of potential target genes are meiosis related genes which code for Argonaute proteins or mitotic division related genes coding for cell cycle proteins [Schurko et al., 2009; Kraaijeveld and Bast, 2012]. Informatively, Wolbachia-induced CI can transit to MK (fig. 2) as was found in 2 Drosophila and 2 moth species. MK occurred when uninfected males of Drosophila subquinaria mated with hybrid females from the cross between Drosophila recens females with the CI phenotype and endosymbiont-uninfected D. subquinaria males [Sasaki et al., 2002, 2005; Jaenike, 2007]. Interestingly, the same transition but in opposite direction from MK to CI occurred in the butterfly Hypolimnas bolina [Hornett et al., 2008]. The suppression of the MK phenotype in infected individuals resulted in male production which upon mating with uninfected females induced CI (fig. 2). These studies suggest that it is relatively easy to shift between MK and CI and point towards similar mechanisms. Transitions can also occur from PI to CI. In Asobara japonica, male offspring produced by PI-Wolbachia-infected females induced (moderate) CI against uninfected females [Kraaijeveld et al., 2011] (fig. 2).

\section{Direct Interference with Doublesex}

Late acting endosymbionts are associated with sexual differentiation and must recognize maleness resulting from male-specifically expressed genes during development. It is now evident that endosymbionts can directly interfere with the expression of sex determination genes. For example, male killing in the moth Ostrinia scapulalis is accomplished by altering the splicing of doublesex [Su- 
gimoto and Ishikawa, 2012]. Altered splicing is also found in the butterfly Eurema mandarina in which Wolbachiainfected genetic males (ZZ) are morphologically and behaviorally fully female and completely fertile. The splicing pattern of the sex-determining gene $d s x$ changes according to the Wolbachia infection status. Intersex individuals express both female and male $d s x$ splice variants. The lethal effects normally occur during late embryonic or early larval developmental stages and might be due to disruption of dosage compensation [Kageyama and Traut, 2004; Narita et al., 2007; Sakamoto et al., 2007; Sugimoto et al., 2010; Sugimoto and Ishikawa, 2012]. It is still unknown whether Wolbachia directly acts on $d s x$ splicing or (more probably) on an upstream splicing regulator of $d s x$ in this female heterogametic system [Beukeboom, 2012]. In the Spiroplasma infected ladybird beetle Anisosticta novemdecimpunctata, males are killed in the early embryonic stage [Tinsley and Majerus, 2006], but the genetic mechanism is still unknown as is true for all MK types in ladybirds [Balayeva et al., 1995; Hurst et al., 1996]. These examples of early MK show that the microbes have evolved different ways of killing males. The MK in Ostrinia is the first well documented case of direct interference of endosymbionts upon host sex determination genes. Due to being the central gear of the key sex determination gene, transformer is expected to be a particularly likely target for such manipulation in holometabolous insect sex determination [Beukeboom, 2012; Negri and Pellecchia, 2012].

\section{Interference during Sexual Differentiation}

Male killing can also occur in the sexual differentiation phase of embryonic or larval development. A functional dosage-compensation complex, a major component of sexual differentiation in Drosophila melanogaster, is required for male killing by Spiroplasma. Spiroplasma failed to kill males lacking any of the 5 proteins required for proper dosage compensation [Veneti et al., 2005]. Dosage compensation is tightly connected with sex determination in Drosophila as the gene sex lethal, which has both a function in dosage compensation and in sex determination, acts as a splice regulator of transformer [Cline, 1984]. Although yet speculative, it may be that the MK Spiroplasma targets the sex lethal gene [Starr and Cline, 2002]. In the mosquito Aedes stimulans, Amblyospora microsporidia kill males in the fourth larval stage [Andreadis, 1985] which is another example of late male killing. Furthermore, an unknown RNA virus was found responsible for late male killing in the oriental tea tortrix, Homona magnanima, in which male death occurs in the larval or pupal stage [Nakanishi et al., 2008].

Endosymbiotic Manipulation of Arthropod Sex Determination
Hormonal signaling pathways are frequently involved in the regulation of symbiotic interactions. In parasitic interactions such as host-parasitoid relationships, they play a central role in synchronizing host and parasite cycles, and manipulation of hormonal signaling by each party has been found [Sagi and Khalaila, 2001; Negri, 2011; Jahnke et al., 2013]. Hormonal signaling as a part of sexual differentiation can also be manipulated by endosymbionts. This is apparent in crustaceans where the establishment of the sexes is a hormonal process. Notably, injection of Wolbachia in young males of A. vulgare induces hypertrophy of the androgenic gland and feminization of tissues [Rigaud and Juchault, 1995]. This result indicates that Wolbachia may interfere with the androgenic hormone receptors and either antagonize the fixation of the androgenic hormone on these receptors or decrease their production. The androgenic hormone is related to insulin and/or insulin-like growth factors which is interesting for 2 reasons. First, Wolbachia has been shown to interact with the insulin pathway in Drosophila [Ikeya et al., 2009]. Even though this pathway is not directly involved in sex determination, insulin-like peptides regulate ecdysteroid synthesis, and recent results indicate that 20-Hydroxyecdysone could play the role of a sex hormone in insects [Negri et al., 2010; Negri and Pellecchia, 2012]. Hormonal manipulation seems mostly associated with feminization, but male killing may also make use of hormonal signals that are different between the sexes. It should, however, be noted that sex determination in insects is generally considered as a cellular genetic process and that the importance of hormonal signaling is still under debate [Steinmann-Zwicky et al., 1989; Schütt and Nöthiger, 2000; Negri and Pellecchia, 2012]. This is informative for the transition between MK and FM which is observed in the moth Ostrinia scapulalis. Antibiotic treatment induced intersex individuals, suggesting that MKinducing Wolbachia were also responsible for feminization [Kageyama and Traut, 2004; Sakamoto et al., 2008; Sugimoto and Ishikawa, 2012]. In addition, transition from PI to FM occurred in the parasitoid wasp Trichogramma kaykai. In T. kaykai with a PI phenotype, diploid intersex individuals were produced under high temperature, suggesting that PI-Wolbachia are also responsible for feminization that is dependent on Wolbachia density [Tulgetske and Stouthamer, 2012] (fig. 2). A small proportion of diploid males is also regularly detected in the parasitoid wasp Asobara japonica which suggests that PIWolbachia are required for feminization and that this effect is dependent on Wolbachia density [W.-J. Ma, unpubl. data]. 


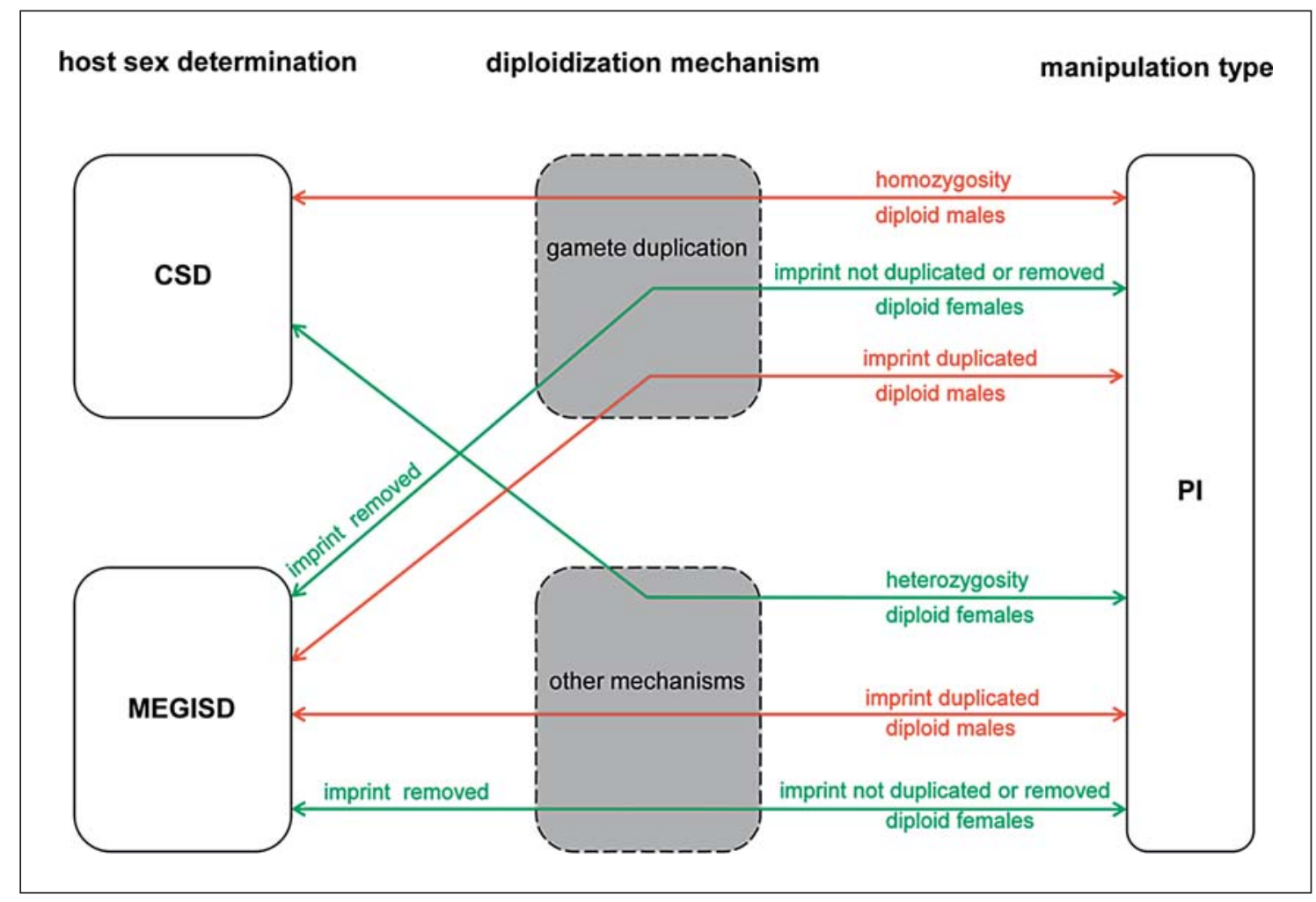

Fig. 3. PI-inducing endosymbionts and haplodiploid host sex determination. $\mathrm{CSD}=$ Complementary sex determination; MEGISD = maternal effect genomic imprinting sex determination. Red arrows: incompatible combinations; green arrows: compatible combinations. CSD is only compatible with PI if diploidization is other than by gamete duplication (e.g. premeiotic doubling, central or terminal fusion). MEGISD species can only have PI if the maternal imprint that prevents female development is not copied during gamete duplication or the endosymbionts remove it before

\section{Interaction between PI Endosymbionts and Host Haplodiploid Sex Determination}

The interaction between endosymbionts and haplodiploid host sex determination is complex, because the mechanisms by which diploidization of the egg takes place also affects the outcome. In some cases it dictates whether particular endosymbionts can establish a certain host phenotype (fig. 3). Several hymenopteran groups have complementary sex determination (CSD) in which sex is determined by the allelic composition of the sex locus: heterozygotes develop into females, hemizygotes and homozygotes into males [Whiting, 1933; Cook, 1993a; Beye et al., 2003]. CSD and PI-inducing endosymbionts that cause gamete duplication are incompatible [Cook, 1993b; van Wilgenburg et al., 2006], or after diploidization. The mode of sex determination and diploidization are mutually informative on each other: in Lepidoptera clavipes and Trichagramma kaykai, PI occurs by gamete duplication and CSD is excluded as sex determination [Schilthuizen et al., 1998; Pannebakker et al., 2004; Tulgetske, 2010], in Asobara japonica CSD is absent and diploidization could occur via gamete duplication [Kremer et al., 2009; Ma et al., 2013], and in Encarsia hispida feminization of diploid males can occur under MEGISD if Cardinium removes the imprint [Giorgini et al., 2009].

because this form of diploidization results in complete homozygosity in most documented species so far [Stouthamer and Kazmer, 1994; Pannebakker et al., 2004; Gottlieb et al., 2002]. The reason is that under CSD diploid homozygotes develop into males, whereas female development is required for PI endosymbionts to invade a host. There is indeed a phylogenetic association between the absence of CSD and the presence of PI endosymbionts [Heimpel and de Boer, 2008]. Interestingly, some CSD species do reproduce parthenogenetically, such as Venturia canescens, but in those species the diploidization mechanism is different (e.g. central or terminal fusion) and apparently retains sex locus heterozygosity [Suomalainen et al., 1987; Beukeboom and Pijnacker, 2000; Mateo-Leach et al., 2009]. Functionally apomictic cloning mechanism is also the case for the 
mite $B$. praetiosa and the parasitoid wasp $N$. formosa [Weeks and Breeuwer, 2001; Adachi-Hagimori et al., 2008].

The other known genetic mechanism of sex determination in Hymenoptera is maternal effect genomic imprinting sex determination (MEGISD). Under MEGISD female development requires a paternal genome for activation of the transformer gene in the zygote which is silenced on the maternal complement [Verhulst et al., 2010; see also Verhulst and van de Zande in this issue]. It has thus far only been documented for Nasonia vitripennis (Chalcidoidea). The broader phylogenetic distribution of the MEGISD model has been challenged, because it is difficult to reconcile with parthenogenetic female reproduction in which a non-imprinted male genome is missing in the egg. One solution would be that the maternally provided imprint is not copied onto the duplicated genome during the diploidization process, providing an active transformer copy to the zygote without fertilization. Under this assumption, PI endosymbionts would be able to infect species with MEGISD. On the other hand, if the maternal imprint would be passed on, zygotic diploidy would result in males and PI by endosymbionts cannot be established (fig. 3). For other forms of diploidization, such as central and terminal fusion, it is necessary to assume that the endosymbionts can remove the maternal imprint, because fusion of 2 meiotic nuclei, each with a maternal imprint, would lead to diploid males. Only gamete duplication without imprint copying alleviates the requirement of endosymbiont interference with MEGISD (fig. 3). Further information is needed on the phylogenetic distribution of the MEGISD system before these issues can be solved.

In the chalcidoid E. hispida, diploid males are produced when females are cured from Cardinium. The type of endosymbiont action, following the above rationale, is thus informative for the sex determination mechanism of this species: it may have MEGISD without the maternal imprint copy (fig. 3, green lines originating from MEGISD). Taking the opposite argumentation, having MEGISD may have prevented it from being infected by PI endosymbionts (fig. 3, red lines originating from MEGISD). How egg diploidization and feminization occurs in this system is not yet known. Removal of the bacteria yields diploid males, indicating that egg diploidy is controlled by the host genotype. Assuming MEGISD, one possibility is that Cardinium prevents transmission of the maternal imprint to the duplicated genome copy, turning diploid male eggs into diploid female eggs.

Endosymbiotic Manipulation of

Arthropod Sex Determination

\section{Conclusion and Future Directions}

Although there have been several reviews on endosymbiotic manipulation of arthropod host reproduction, we have taken a specific focus on the mechanisms by which endosymbionts may interfere with host sex determination. From considering the 4 major endosymbiotic manipulation types, it is clear that diverse endosymbionts can target the host at different developmental stages, ranging from the spermatogenesis stage or the first mitotic division to the late pupal stage. The evolution of similar manipulation types in distantly related endosymbiont taxa shows that convergent evolution has probably occurred repeatedly. Many of the intricacies of endosymbiont-host interactions remain to be discovered, because in most instances it is still unknown what developmental pathways are exploited by the endosymbionts to exert their effects on host reproduction. We have proposed that the transitions between endosymbiont phenotypes suggest partly similar mechanisms for apparently divergent phenotypes. We have also argued that the mechanism of endosymbiotic manipulation must be considered in the context of the host sex determination mechanism and that both of these processes may be mutually informative on each other.

With the development of next-generation DNA sequencing techniques, it is getting easier to acquire genomic information on non-model organisms which makes the unraveling of the genetic basis of endosymbiotic manipulation very promising and exciting. A first question to answer is whether the diversity of effects and the variation of microorganisms involved reflect true convergence or merely horizontal gene transfer between symbionts. Future studies should compare different endosymbiont genomes for gene composition as well as gene products that might affect developmental pathways of their hosts [e.g. Moreno et al., 2011]. For instance, the comparison of genomes between Wolbachia and Cardinium suggests that CI has an evolutionary independent origin in these 2 symbionts and reveals no evidence for recent horizontal gene transfer [Penz et al., 2012]. Comparison of transcriptomes and proteomes of infected and uninfected hosts may also be rewarding [e.g. McNulty et al., 2012]. Moreover, the integration of knowledge about evolutionary dynamics and genomic data should make it possible to identify genomic signatures that can lead to the identification of genes involved in host reproduction and sex determination manipulation. Attention should be paid to host sex determination genes such as transformer and doublesex, candidate targets for disruption by 
endosymbionts, whose regulation may be altered in several ways, including their sex-specific splicing or imprinting. In addition, cell cycle genes involved in meiosis and mitosis, particularly those related to histone regulation or genes coding for Argonaute proteins, are good candidates [Kraaijeveld and Bast, 2012].

There is growing evidence for epigenetic control of developmental processes in insects [Lyko and Maleszka, 2011] as well as in host-parasite interactions [GómezDíaz et al., 2012]. Given the evolution of multiple reproductive manipulations, it is tempting to propose that these phenotypes may actually be mechanistically very close to other physiological mechanisms involved in hostparasite interactions that could represent pre-adaptations to reproductive manipulations [Vavre et al., 2003]. As reproductive manipulations often involve parental effects, epigenetic manipulation by endosymbionts clearly requires attention. An obvious candidate is chromatin remodeling which can lead to alteration of chromosomal behavior as well as to variation in gene expression or splicing processes. It is thus possible that many of the symbiont phenotypes rely on epigenetic mechanisms, particularly those related to histone regulation. Moreover, paternal effects of $\mathrm{CI}$, maternal effects of PI, and mechanisms of early MK may all involve some form of genomic imprinting [Werren, 2011; Negri and Pellecchia, 2012; Rabeling and Kronauer, 2013]. The currently strongest evidence for a role of epigenetics was found by Negri et al. [2009] who showed that Wolbachia interferes with host sexual differentiation in the leafhopper $Z$. pullula by disrupting methylation patterns and genetic imprinting. In Drosophila species, Wolbachia prophage DNA adenine methyltransferase genes might be involved in the modification or rescue process of CI [Saridaki et al., 2011]. These studies are first indications for a role of epigenetics in host manipulation, but we are only at the beginning of elucidating the precise molecular and biochemical pathways involved. Technological developments now allow for easier characterization of epigenetic marks, and transcriptome and proteome comparison of infected and uninfected individuals in various systems may be a promising way forward. Without doubt, more mechanistic studies of host reproduction manipulation are going to reveal novel and intriguing insights into the co-evolution between host and endosymbiont reproduction.

\section{Acknowledgements}

We thank Ken Kraaijeveld for input on molecular mechanisms of endosymbiotic manipulation, Eveline Verhulst, Louis van de Zande, and Bart Pannebakker for discussion on sex determination, and an anonymous reviewer for constructive criticism. The research was supported by TOP grant No. ALW 854.10.001 of the Netherlands Organization for Scientific Research to Leo Beukeboom, the Agence National de la Recherche (ANR-2010BLAN-170101) to Fabrice Vavre, and the Van Gogh grant for French-Dutch collaboration to Fabrice Vavre and Bart Pannebakker.

\section{References}

Adachi-Hagimori T, Miura K, Stouthamer R: A new cytogenetic mechanism for bacterial endosymbiont-induced parthenogenesis in $\mathrm{Hy}$ menoptera. Proc Biol Sci 275:2667-2673 (2008).

-Andreadis TG: Experimental transmission of a microsporidian pathogen from mosquitoes to an alternate copepod host. Proc Natl Acad Sci USA 82:5574-5577 (1985).

Arakaki N, Miyoshi T, Noda H: Wolbachia-mediated parthenogenesis in the predatory thrips Franklinothrips vespiformis (Thysanoptera: Insecta). Proc Biol Sci 268:1011-1016 (2001).

Balayeva NM, Eremeeva ME, Zakharov IA: Genotype characterization of the bacterium expressing the male-killing trait in the ladybird beetle Adalia bipunctata with specific rickettsial molecular tools. Appl Environ Microbiol 61:1431-1437 (1995).

Beukeboom LW: Microbial manipulation of host sex determination. Endosymbiotic bacteria can directly manipulate their host's sex determination towards the production of female offspring. BioEssays 34:484-488 (2012).

Beukeboom LW, Pijnacker LP: Automictic parthenogenesis in the parasitoid Venturia canescens (Hymenoptera: Ichneumonidae) revisited. Genome 43:939-944 (2000).

Beukeboom LW, Perrin N: Evolution of Sex Determination (Oxford University Press, Oxford 2014, in press).

Beye M, Hasselmann M, Fondrk MK, Page RE, Omholt SW: The gene $c s d$ is the primary signal for sexual development in the honeybee and encodes an SR-type protein. Cell 114: 419-429 (2003).

Blackman RL: Sex determination in insects, in Hardie J, Leather SR (eds): Insect Reproduction, pp 57-94 (CRC Press, Boca Raton 1995).

Bonte D, Hovestadt T, Poethke HJ: Male-killing endosymbionts: influence of environmental conditions on persistence of host metapopulation. BMC Evol Biol 8:243 (2008).

- Bouchon D, Rigaud T, Juchault P: Evidence for widespread Wolbachia infection in isopod crustaceans: molecular identification and host feminization. Proc Biol Sci 265:10811090 (1998).

Bouchon D, Cordaux R, Greve P: Feminizing Wolbachia and the evolution of sex determination in isopods, in Bourtzis K, Miller T (eds): Insect Symbiosis, pp 273-294 (Taylor and Francis Group LLC, Boca Raton 2008).

Breeuwer JA: Wolbachia and cytoplasmic incompatibility in the spider mites Tetranychus urticae and T. turkestani. Heredity 79:41-47 (1997).

- Breeuwer JA, Werren JH: Microorganisms associated with chromosome destruction and reproductive isolation between two insect species. Nature 346:558-560 (1990). 
Breeuwer JA, Werren JH: Cytoplasmic incompatibility and bacterial density in Nasonia vitripennis. Genetics 135:565-574 (1993).

Bull JJ: Sex determining mechanisms: an evolutionary perspective. Experimentia 41:12851295 (1985).

Bulnheim HP, Vávra J: Infection by the microsporidian Octosporea effeminans in the amphipod Gammarus duebeni. J Parasitol 54:241248 (1968).

Charlat S, Davies N, Roderick GK, Hurst GD: Disrupting the timing of Wolbachia-induced male-killing. Biol Lett 3:154-156 (2007).

-Cline TW: Autoregulatory functioning of a Drosophila gene product that establishes and maintains the sexually determined state. Genetics 107:231-277 (1984).

Cook JM: Sex determination in the Hymenoptera, a review of models and evidence. Heredity 71 : 421-435 (1993a).

Cook JM: Experimental tests of sex determination in Goniozus nephantidis (Hymenoptera, Bethylidae). Heredity 71:130-137 (1993b).

Cordaux R, Bouchon D, Grève P: The impact of endosymbionts on the evolution of host sexdetermination mechanisms. Trends Genet 27:332-341 (2011).

Douglas AE: Nutritional interactions in insectmicrobial symbioses: aphids and their symbiotic bacteria Buchnera. Annu Rev Entomol 43:17-37 (1998).

Duron O, Bouchon D, Boutin S, Bellamy L, Zhou $\mathrm{L}$, et al: The diversity of reproductive parasites among arthropods: Wolbachia do not walk alone. BMC Biol 6:27 (2008).

Ferree PM, Avery A, Azpurua J, Wilkes T, Werren $\mathrm{JH}$ : A bacterium targets maternally inherited centrosomes to kill males in Nasonia. Curr Biol 18:1409-1414 (2008).

-Fong DW, Kane TC, Culver DC: Vestigialization and loss of nonfunctional characters. Annu Rev Ecol Syst 26:249-268 (1995).

Fontanetti CS, Campos KA, Prado RA, da Silva Souza T: Cytogenetic studies in Diplopoda. Cytologia 67:253-260 (2002).

-Gempe T, Beye M: Function and evolution of sex determination mechanisms, genes and pathways in insects. BioEssays 33:52-60 (2011).

Giorgini M, Monti MM, Caprio E, Stouthamer R, Hunter MS: Feminization and the collapse of haplodiploidy in an asexual parasitoid wasp harboring the bacterial symbiont Cardinium. Heredity 102:365-371 (2009).

-Giorgini M, Bernardo U, Monti MM, Nappo AG, Gebiola M: Rickettsia symbionts cause parthenogenetic reproduction in the parasitoid wasp Pnigalio soemius (Hymenoptera: Eulophidae). Appl Environ Microbiol 76:25892599 (2010).

Gómez-Díaz E, Jordà M, Peinado MA, Rivero A: Epigenetics of host-pathogen interactions: the road ahead and the road behind. PLoS Pathog 8:e1003007 (2012).

Gottlieb Y, Zchori-Fein E, Werren JH, Karr TL: Diploidy restoration in Wolbachia-infected Muscidifurax uniraptor (Hymenoptera: Pteromalidae). J Invert Pathol 81:166-174 (2002).
Graham P, Penn JK, Schedl P: Masters change, slaves remain. Bioessays 25:1-4 (2002).

Groot TVM, Breeuwer JAJ: Cardinium symbionts induce haploid thelytoky in most clones of three closely related Brevipalpus species. Exp Appl Acarol 39:257-271 (2006).

Heimpel GE, de Boer JG: Sex determination in the hymenoptera. Annu Rev Entomol 53:209230 (2008).

Hornett EA, Duplouy AM, Davies N, Roderick GK, Wedell N, et al: You can't keep a good parasite down: evolution of a male-killer suppressor uncovers cytoplasmic incompatibility. Evolution 62:1258-1263 (2008).

Hunter MS, Perlman SJ, Kelly SE: A bacterial symbiont in the Bacteroidetes induces cytoplasmic incompatibility in the parasitoid wasp Encarsia pergandiella. Proc Biol Sci 270: 2185-2190 (2003).

Hurst GD, Jiggins FM: Male-killing bacteria in insects: mechanisms, incidence, and implications. Emerg Infect Diseases 6:329-336 (2000).

Hurst GD, Werren JH: The role of selfish genetic elements in eukaryotic evolution. Nature Rev Genet 2:597-606 (2001).

Hurst GD, Hammarton TC, Obrycki JJ, Majerus TMO, Walker LE, et al: Male-killing bacterium in a fifth ladybird beetle, Coleomegilla maculata (Coleoptera: Coccinellidae). Heredity 77:177-185 (1996).

- Hurst GD, Jiggins FM, Pomiankowski A: Which way to manipulate host reproduction? Wolbachia that cause cytoplasmic incompatibility are easily invaded by sex ratio-distorting $\mathrm{mu}$ tants. Am Nat 160:360-373 (2002).

Hurst LD: The incidences and evolution of cytoplasmic male killers. Proc Biol Sci 244:91-99 (1991).

Ikeya T, Broughton S, Alic N, Grandison R, Partridge L: The endosymbiont Wolbachia increases insulin/IGF-like signalling in Drosophila. Proc Biol Sci 276:3799-3807 (2009).

Jaenike J: Spontaneous emergence of a new Wolbachia phenotype. Evolution 61:2244-2252 (2007).

Jahnke M, Smith JE, Dubuffet A, Dunn AM: Effects of feminizing microsporidia on the masculinizing function of the androgenic gland in Gammarus duebeni. J Invertebr Pathol 112: 146-151 (2013).

Juchault P, Mocquard JP: Transfer of a parasitic sex factor to the nuclear genome of the host : a hypothesis on the evolution of sex-determining mechanisms in the terrestrial isopod Armadillidium vulgare Latr. J Evol Biol 6: 511-528 (1993).

Kageyama D, Traut W: Opposite sex-specific effects of Wolbachia and interference with the sex determination of its host Ostrinia scapulalis. Proc Biol Sci 271:251-258 (2004).

Kageyama D, Hoshizaki S, Ishikawa Y: Femalebiased sex ratio in the Asian corn borer Ostrinia furnacalis: evidence for the occurrence of feminizing bacteria in an insect. Heredity 81:311-316 (1998).
Kageyama D, Anbutsu H, Shimada M, Fukatsu T: Spiroplasma infection causes either early or late male killing in Drosophila, depending on maternal host age. Naturwissenschaften 94: 333-337 (2007).

Kageyama D, Narita S, Watanabe M: Insect sex determination manipulated by their endosymbionts: incidences, mechanisms and implications. Insects 3:161-199 (2012).

Kato Y, Kobayashi K, Oda S, Tatarazako N, Watanabe $H$, Iguchi $T$ : Sequence divergence and expression of a transformer gene in the branchiopod crustacean, Daphnia magna. Genomics 95:160-165 (2010).

Koga R, Tsuchida T, Fukatsu T: Changing partners in an obligate symbiosis: a facultative endosymbiont can compensate for loss of the essential endosymbiont Buchnera in an aphid. Proc Biol Sci 270:2543-2550 (2003).

Kraaijeveld K, Bast J: Transposable element proliferation as a possible side effect of endosymbiont manipulations. Mob Genet Elements 253-256 (2012).

Kraaijeveld K, Reumer BM, Mouton L, Kremer N, Vavre F, van Alphen JJ: Does a parthenogenesis-inducing Wolbachia induce vestigial cytoplasmic incompatibility? Naturwissenschaften 98:175-180 (2011).

Kremer N, Charif D, Henri H, Bataille M, Prévost $\mathrm{G}$, et al: A new case of Wolbachia dependence in the genus Asobara: evidence for parthenogenesis induction in Asobara japonica. Heredity 103:248-256 (2009).

Landmann F, Orsi GA, Loppin B, Sullivan W: Wolbachia-mediated cytoplasmic incompatibility is associated with impaired histone deposition in the male pronucleus. PLoS Pathog 5:e1000343 (2009).

-Legrand JJ, Legrand-Hamelin E, Juchault P: Sex determination in crustacea. Biol Rev 62:439470 (1987).

Lyko F, Maleszka R: Insects as innovative models for functional studies of DNA methylation. Trends Genet 27:127-131 (2011).

Ma WJ, Kuijper B, De Boer JG, Van de Zande L, Beukeboom LW, et al: Absence of complementary sex determination in the parasitoid wasp genus Asobara (Hymenoptera: Braconidae). PLoS One 8:e60459 (2013).

Marín I, Baker BS: The evolutionary dynamics of sex determination. Science 281:1990-1994 (1998).

Mateo-Leach I, Pannebakker BA, Schneider MV, Driessen G, Van de Zande L, Beukeboom LW: Thelytoky in Hymenoptera with Venturia canescens and Leptopilina clavipes as case studies, in Schön I, Martens K, Dijk P (eds): Lost Sex, pp 347-375 (Springer Netherlands, Dordrecht 2009).

McNulty SN, Abubucker S, Simon GM, Mitreva M, McNulty NP, et al: Transcriptomic and proteomic analyses of a Wolbachia-Free filarial parasite provide evidence of trans-kingdom horizontal gene transfer. PLoS One 7:e45777 (2012). 
Moreno Y, Gros PP, Tam M, Segura M, Valanparambil R, et al: Proteomic analysis of excretory-secretory products of Heligmosomoides polygyrus assessed with next-generation sequencing transcriptomic information. PLoS Negl Trop Dis 5:e1370 (2011).

-Mouton L, Henri H, Bouletreau M, Vavre F: Multiple infections and diversity of cytoplasmic incompatibility in a haplodiploid species. Heredity 94:187-192 (2005).

-Nakanishi K, Hoshino M, Nakai M, Kunimi Y: Novel RNA sequences associated with late male killing in Homona magnanima. Proc Biol Sci 275:1249-1254 (2008)

- Narita S, Kageyama D, Nomura M, Fukatsu T: Unexpected mechanism of symbiont-induced reversal of insect sex: feminizing Wolbachia continuously acts on the butterfly Eurema hecabe during larval development. Appl Environ Microbiol 73:4332-4341 (2007).

Negri I: Wolbachia as an 'infectious' extrinsic factor manipulating host signaling pathways. Front Endocrinol 2:115 (2011).

Negri I, Pellecchia M: Sex steroids in insects and the role of the endosymbiont Wolbachia: a new perspective, in Dubey RK (ed): Sex Hormones, pp 353-374 (InTech, Winchester 2012).

-Negri I, Pellecchia M, Mazzoglio PJ, Patetta A, Alma A: Feminizing Wolbachia in Zyginidia pullula (Insecta, Hemiptera), a leafhopper with an XX/X0 sex-determination system. Proc Biol Sci 273:2409-2416 (2006).

- Negri I, Franchini A, Gonella E, Daffonchio D, Mazzoglio PJ, et al: Unravelling the Wolbachia evolutionary role: the reprogramming of the host genomic imprinting. Proc Biol Sci 276:2485-2491 (2009).

- Negri I, Pellecchia M, Grève P, Daffonchio D, Bandi C, Alma A: Sex and stripping: the key to the intimate relationship between Wolbachia and host? Commun Integr Biol 3:110115 (2010).

Norton RA, Kethley JB, Johnston DE, O’ Connor BM: Phylogenetic perspectives on genetic systems of reproductive modes of mites, in Wrensch DL, Ebbert DL (eds): Evolution and Diversity of Sex Ratio in Mites and Insects, pp 8-99 (Chapman \& Hall, New York 1993).

-Nöthiger R, Steinmann-Zwicky M: A single principle for sex determination in insects. Cold Spring Harb Symp Quant Biol 50:615-621 (1985).

-O’Neill SL, Giordano R, Colbert AM, Karr TL, Robertson HM: 16S rRNA phylogenetic analysis of the bacterial endosymbionts associated with cytoplasmic incompatibility in insects. Proc Natl Acad Sci USA 89:2699-2702 (1992).

- Pannebakker BA, Pijnacker LP, Zwaan BJ, Beukeboom LW: Cytology of Wolbachia-induced parthenogenesis in Leptopilina clavipes (Hymenoptera: Figitidae). Genome 303:299-303 (2004).

-Partridge L, Hurst LD: Sex and conflict. Science 281:2003-2008 (1998)
Penz T, Schmitz-Esser S, Kelly SE, Cass BN, Müller A, et al: Comparative genomics suggests an independent origin of cytoplasmic incompatibility in Cardinium hertigii. PLoS Genet 8:e1003012 (2012).

- Perrot-Minnot M-J, Migeon A, Navajas M: Intergenomic interactions affect female reproduction: evidence from introgression and inbreeding depression in a haplodiploid mite. Heredity 93:551-558 (2002).

Rabeling C, Kronauer DJ: Thelytokous parthenogenesis in eusocial Hymenoptera. Annu Rev Entomol 58:273-292 (2013).

Raychoudhury R, Werren JH: Host genotype changes bidirectional to unidirectional cytoplasmic incompatibility in Nasonia longicornis. Heredity 108:105-114 (2012).

Raymond CS, Shamu CE, Shen MM, Seifert KJ, Hirsch B, et al: Evidence for evolutionary conservation of sex-determining genes. Nature 391:691-695 (1998).

Rideout EJ, Dornan AJ, Neville MC, Eadie S, Goodwin SF: Control of sexual differentiation and behavior by the doublesex gene in Drosophila melanogaster. Nat Neurosci 13:458466 (2010).

Rigaud T: Inherited microorganisms and sex determination of the hosts, in O'Neill SL, Hoffmann AA, Werren JH (eds): Influential Passengers: Inherited Microorganisms and Arthropod Reproduction, pp 81-101 (Oxford University Press, Oxford 1997).

Rigaud T, Juchault P: Success and failure of horizontal transfers of feminizing Wolbachia endosymbionts in woodlice. J Evol Biol 8:249255 (1995).

Riparbelli MG, Giordano R, Ueyama M, Callaini G: Wolbachia-mediated male killing is associated with defective chromatin remodeling. PloS One 7:e30045 (2012).

Rodgers-Gray TP, Smith JE, Ashcroft AE, Isaac RE, Dunn AM: Mechanisms of parasite-induced sex reversal in Gammarus duebeni. Int J Parasitol 34:747-753 (2004).

Saccone G, Pane A, Polito LC: Sex determination in flies, fruitflies and butterflies. Genetica 116: 15-23 (2002).

Sagi A, Khalaila I: The crustacean androgen: a hormone in an isopod and androgenic activity in decapods. Amer Zool 41:477-484 (2001).

-Sakamoto H, Kageyama D, Hoshizaki S, Ishikawa Y: Sex-specific death in the Asian corn borer moth (Ostrinia furnacalis) infected with Wolbachia occurs across larval development. Genome 50:645-652 (2007).

Sakamoto H, Kageyama D, Hoshizaki S, Ishikawa Y: Heat treatment of the Adzuki bean borer, Ostrinia scapulalis, infected with Wolbachia gives rise to sexually mosaic offspring. J Insect Sci 8:1-5 (2008).

-Sánchez L: Sex-determining mechanisms in insects. Int J Dev Biol 52:837-856 (2008).

-Saridaki A, Sapountzis P, Harris HL, Batista PD, Biliske JA, et al: Wolbachia prophage DNA adenine methyltransferase genes in different Drosophila-Wolbachia associations. PloS One 6:e19708 (2011).
Sasaki T, Kubo T, Ishikawa H: Interspecific transfer of Wolbachia between two lepidopteran insects expressing cytoplasmic incompatibility: a Wolbachia variant naturally infecting Cadra cautella causes male killing in Ephestia kuehniella. Genetics 162:1313-1319 (2002).

-Sasaki T, Massaki N, Kubo T: Wolbachia variant that induces two distinct reproductive phenotypes in different hosts. Heredity 95:389-393 (2005).

Schilthuizen M, Honda J, Stouthamer R: Parthenogenesis inducing Wolbachia in Trichogramma kaykai. Ann Entomol Soc Am 91: 410-414 (1998).

-Schurko AM, Logsdon JM, Eads BD: Meiosis genes in Daphnia pulex and the role of parthenogenesis in genome evolution. BMC Evol Biol 9:78 (2009).

Schütt C, Nöthiger R: Structure, function and evolution of sex-determining systems in Dipteran insects. Development 127:667-677 (2000).

-Schwander T, Crespi BJ, Gries R, Gries G: Neutral and selection-driven decay of sexual traits in asexual stick insects. Proc Biol Sci 280: 20130823.

-Serbus LR, Casper-Lindley C, Landmann F, Sullivan W: The genetics and cell biology of $\mathrm{Wol}$ bachia-host interactions. Ann Rev Genet 42: 683-707 (2008).

-Starr DJ, Cline TW: A host-parasite interaction rescues Drosophila oogenesis defects. Nature 418:76-79 (2002).

-Steinmann-Zwicky M, Schmid H, Nöthiger R: Cell-autonomous and inductive signals can determine the sex of the germ line of Drosophila by regulating the gene $S x l$. Cell 57:157-166 (1989).

-Stenberg P, Saura A: Cytology of asexual animals, in Schon I, Martens K, Peter D (eds): Lost Sex, pp 63-74 (Springer Netherlands, Dordrecht 2009).

Stouthamer R, Kazmer DJ: Cytogenetics of microbe-associated parthenogenesis and its consequences for gene flow in Trichogramma wasps. Heredity 73:317-327 (1994).

Stouthamer R, Russell JE, Vavre F, Nunney L: Intragenomic conflict in populations infected by parthenogenesis inducing Wolbachia ends with irreversible loss of sexual reproduction. BMC Evol Biol 10:229 (2010).

-Sugimoto TN, Ishikawa Y: A male-killing Wolbachia carries a feminizing factor and is associated with degradation of the sex-determining system of its host. Biol Lett 8:412-415 (2012).

- Sugimoto TN, Fujii T, Kayukawa T, Sakamoto H, Ishikawa Y: Expression of a doublesex homologue is altered in sexual mosaics of Ostrinia scapulalis infected with Wolbachia. Insect Biochem Mol Biol 40:847-854 (2010).

Suomalainen E, Saura A, Lokki J: Cytology and Evolution in Parthenogenesis, pp 23-52 (CRC Press, Boca Raton 1987).

Suzuki MG, Ohbayashi F, Mita K, Shimada T: The mechanism of sex-specific splicing at the doublesex gene is different between Drosophila melanogaster and Bombyx mori. Insect Biochem Mol Biol 31:1201-1211 (2001). 
-Suzuki MG, Imanishi S, Dohmae N, Nishimura T, Shimada T, Matsumoto S: Establishment of a novel in vivo sex-specific splicing assay system to identify a trans-acting factor that negatively regulates splicing of Bombyx mori dsx female exons. Mol Cell Biol 28:333-343 (2008).

Terry RS, Smith JE, Dun AM: Impact of a novel feminising microsporidium on its crustacean host. J Euk Microbiol 45:497-501 (1998).

- Tinsley MC, Majerus MEN: A new male-killing parasitism: Spiroplasma bacteria infect the ladybird beetle Anisosticta novemdecimpunctata (Coleoptera: Coccinellidae). Parasitology 132:757-765 (2006).

Tram U, Sullivan W: Role of delayed nuclear envelope breakdown and mitosis in Wolbachiainduced cytoplasmic incompatibility. Science 296:1124-1126 (2002).

- Tram U, Fredrick K, Werren JH, Sullivan W: Paternal chromosome segregation during the first mitotic division determines Wolbachiainduced cytoplasmic incompatibility phenotype. J Cell Sci 119:3655-3663 (2006).

Tulgetske GM: Investigation into the mechanisms of Wolbachia induced parthenogenesis and sex determination in the parasitoid wasp Trichogramma. $\mathrm{PhD}$ thesis (University of California, Riverside 2010).

- Tulgetske GM, Stouthamer R: Characterization of intersex production in Trichogramma kaykai infected with parthenogenesis-inducing Wolbachia. Naturwissenschaften 99: 143-152 (2012).

Turelli M, Hoffmann AA: Cytoplasmic incompatibility in Drosophila simulans: dynamics and parameter estimates from natural populations. Genetics 140:1319-1338 (1995). van Wilgenburg E,Driessen G, Beukeboom LW: Single locus complementary sex determination in Hymenoptera: an 'unintelligent' design. Front Zool 3:1 (2006).

-Vavre F, Fleury F, Varaldi J, Fouillet P, Boulétreau M: Evidence for female mortality in Wolbachia-mediated cytoplasmic incompatibility in haplodiploid insects: epidemiologic and evolutionary consequences. Evolution 54:191200 (2000).

Vavre F, Dedeine F, Quillon M, Fouillet P, Fleury F, et al: Within-species diversity of Wolbachia-induced cytoplasmic incompatibility in haplodiploid insects. Evolution 55:1710-1714 (2001).

Vavre F, Fouillet P, Fleury F: Between- and within-host species selection on cytoplasmic incompatibility-inducing Wolbachia in haplodiploids. Evolution 57:421-427 (2003).

Veneti Z, Bentley JK, Koana T, Braig HR, Hurst GD: A functional dosage compensation complex required for male killing in Drosophila. Science 307:1461-1463 (2005).

Ventura T, Rosen O, Sagi A: From the discovery of the crustacean androgenic gland to the insulin-like hormone in six decades. Gen Comp Endocr 173:381-388 (2011).

-Verhulst EC, Beukeboom LW, van de Zande L: Maternal control of haplodiploid sex determination in the wasp Nasonia. Science 328:620623 (2010).

Waterbury JA, Jackson LL, Schedl P: Analysis of the doublesex female protein in Drosophila melanogaster: role in sexual differentiation and behavior and dependence on intersex. Genetics 152:1653-1667 (1999).

-Weeks AR, Breeuwer JA: Wolbachia-induced parthenogenesis in a genus of phytophagous mites. Proc Biol Sci 268:2245-2251 (2001).
Weeks AR, Marec F, Breeuwer JA: A mite species that consists entirely of haploid females. Science 292:2479-2482 (2001).

Werren JH: Biology of Wolbachia. Annu Rev Entomol 42:587- 609 (1997).

Werren JH: Selfish genetic elements, genetic conflict, and evolutionary innovation. Proc Natl Acad Sci USA 108:10863-10870 (2011).

Werren JH, O’Neill SL: The evolution of heritable symbionts, in O'Neill SL, Hoffmann AA, Werren JH (eds): Influential Passengers Inherited Microorganisms and Arthropod Reproduction, pp 1-41 (Oxford University Press, Oxford 1997).

Werren JH, Beukeboom LW: Sex determination, sex ratios, and genetic conflict. Annu Rev Ecol Syst 29:233-261 (1998).

Werren JH, Baldo L, Clark ME: Wolbachia: master manipulators of invertebrate biology. Nat Rev Microbiol 6:741-751 (2008).

Whiting PW: Selective fertilization and sex-determination in Hymenoptera. Science 78:537538 (1933).

Wilkins AS: Moving up the hierarchy: a hypothesis on the evolution of a genetic sex determination pathway. BioEssays 17:71-77 (1995).

Zchori-Fein E, Perlman SJ: Distribution of the bacterial symbiont Cardinium in arthropods. Mol Ecol 13:2009-2016 (2004).

Zchori-Fein E, Gottlieb Y, Kelly SE, Brown JK, Wilson JM, et al: A newly discovered bacterium associated with parthenogenesis and a change in host selection behavior in parasitoid wasps. Proc Natl Acad Sci USA 98:1255512560 (2001).

Zug R, Hammerstein P: Still a host of hosts for Wolbachia: analysis of recent data suggests that $40 \%$ of terrestrial arthropod species are infected. PLoS One 7:e38544 (2012). 